\title{
CONTRIBUIÇÃO AO CONHECIMENTO DA DIATOMOFLÓRULA DO CONTEÚDO ESTOMACAL DE ALGUMAS ESPÉCIES DE PEIXES DA AMAZÔNIA. I - MULEUS SP. (PACU) DO LAGO DO PRATO, AM., BRASIL.
}

\author{
Roseli Maria de SOUZA-MOSIMANN', Aldalea Sprada TAVARES ${ }^{2}$, Vilma \\ Pereira FREITAS ${ }^{3}$
}

RESUMO - Um estudo taxonômico da flora de diatomáceas (Bacillariophyceae) no conteúdo estomacal de Myleus sp. (Pacú), do lago do Prato, no Arquipélago de Anavilhanas - Rio Negro Amazônia $\left(60^{\circ} 45^{\prime} \mathrm{W} 2^{\circ} 43^{\prime} \mathrm{S}\right)$ é apresentado. Foram identificados 32 táxons específicos e infraespecificos, distribuidos em 10 gêneros e 5 famílias. Eunotia foi o gênero melhor representado.

Palavras-Chaves: Diatomáceas de água doce, Bacillariophyceae, Conteúdo estomacal de peixes.

Contribution to the Knowledge of the Diatom Florule from the Stomach Contents of Fish Species in Amazonia. I - Myleus sp. (Pacu) of Lago do Prato, AM., Brazil.

ABSTRACT - A taxonomic survey of the diatom flora (Bacillariophyceae) of the stomach contens of Myleus sp. (Pacú), of the Lago do Prato, Arquipélago de Anavilhanas - Rio Negro Amazônia $\left(60^{\circ} 45^{\prime} \mathrm{W}\right.$ and $\left.2^{\circ} 43^{\prime} \mathrm{S}\right)$ is presented. There were identified 32 specific and infra-specific taxa, distributed in 10 genera and 5 families. Eunotia were the best represented genera.

Key Words: Fresh water Diatoms, Bacillariophyceae, Stomach contents, Fishes.

\section{INTRODUÇÃO}

São escassos os trabalhos que tratam exclusivamente da taxônomia das diatomáceas (Bacillariophyceae) para a Amazônia. Conhece-se os trabalhos de HUSTEDT (1952a; 1952b) e recentemente o trabalho de DE OLIVEIRA et al. (1992) para a Amazônia Equatoriana. Referências as diatomáceas também são feitas em trabalhos sobre fictoplâncton geral como UHERKOVICH \& SCHIMIDT (1974) no Solimões e Lago do Castanho; UHERKOVICH (1976) nos Rios Negro e Tapajós; UHERKOVICH \& RAI (1979) para outros rios secundários e Rio Negro e UHERKOVICH \& FRANKEN (1980) em Igarapés da
Amazônia Central. DE OLIVEIRA et al. (1992) comentam que dentre alguns grupos de algas, as diatomáceas (Bacillariophyceae) são provavelmente os últimos a serem conhecidos.

O Lago do Prato, localizado no Arquipélago de Anavilhanas -Rio Negro Amazônia a 60\%5'W e 243'S (Mapa 1), é habitat natural de muitas espécies de peixes de alto valor comercial. Estudos ecofisiológicos estão sendo realizados exaustivamente nesta área, em cooperação com o Instituto Max-Planck (Alemanha) e o Instituto Nacional de Pesquisas da Amazônia (INPA).

A presença de muitos peixes de hábitos iliófagos neste local tornam necessários estudos do conteúdo

\footnotetext{
Horto Botânico - UFSC - Trindade. Cx. Postal 476, CEP 88040-970, Florianópilis,SC,Brasil.

INPA - Cx. Postal 478, CEP 69011-970, Manaus,Amazonas,Brasil.

Rua Recife 3280 - IMA - Flores,Amazonas,Brasil.
} 


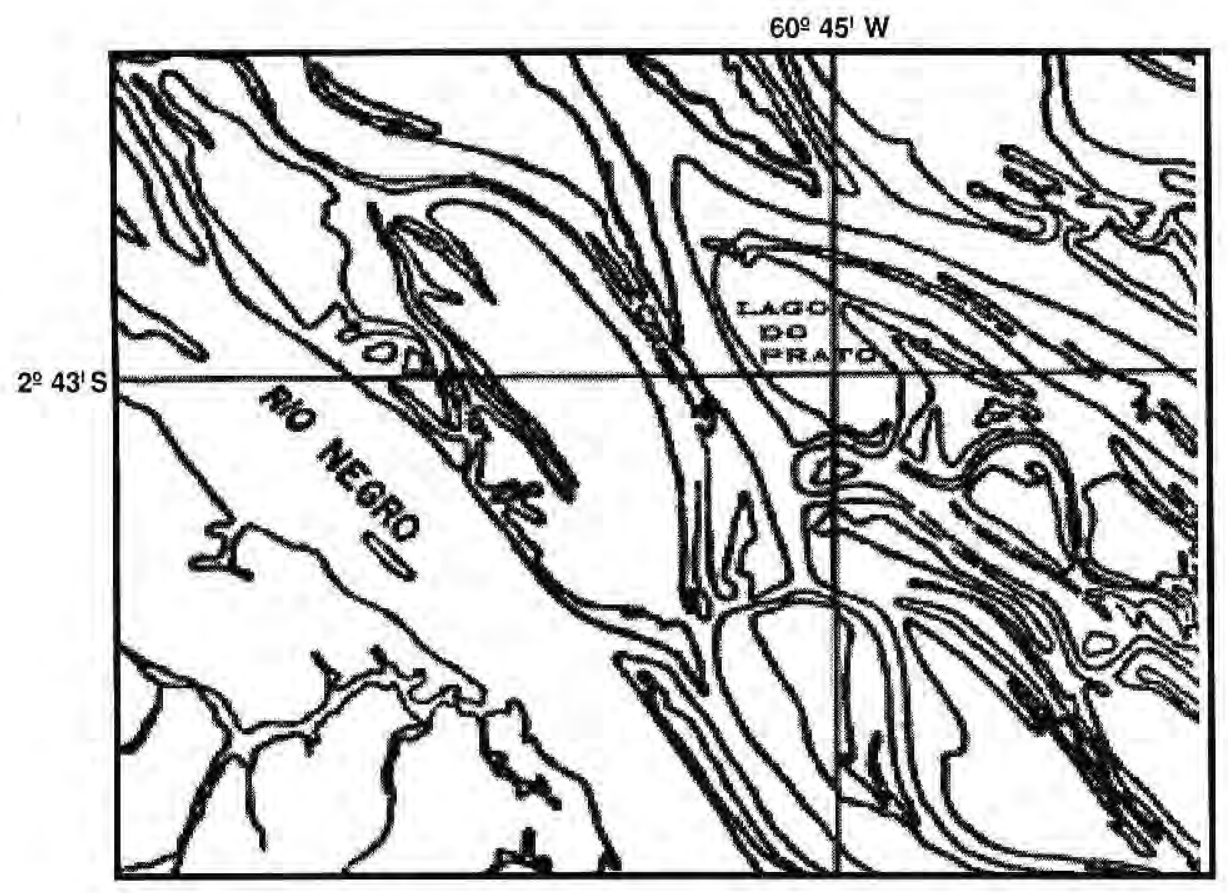

Mapa 1. Localização da região de coleta.

estomacal dos mesmos para que se possa melhor conhecer as preferências alimentares de tais peixes.

Neste trabalho inicial, analisamos o conteúdo estomacal do peixe conhecido na região como Pacu (Myleus sp.).

\section{MATERIAL E MÉTODOS}

Foram analisados o conteúdo estomacal de peixes $2151 ; 2154 ; 2156$; $2159 ; 2163 ; 2193 ; 2201 ; 2222 ; 2191$; e 2153 da Coleção Ulle, depositada no INPA correspondendo as lâminas de número: $12.725,12.726,12.727,12.728$, $12.729,12.730,12.731,12.732 ; 12.733$ e 12.734 respectivamente, depositadas no Herbário FLOR do Horto Botânico da Universidade Federal de Santa Catarina. O conteúdo dos estômagos dos peixes, fixado em álcool $7 \%$, foi lavado em água destilada e, após, oxidado segundo a técnica de SIMONSEN (1974) modificada por MOREIRA FILHO (1982).

A análise das lâminas foi realizada em microscópio binocular Olympus, Modelo CBB, com câmara clara e disco micrometrado acoplados.As ilustrações fotográficas foram obtidas em fotomicroscópic marca Jenalumar.com contraste de fase e fotomicroscópio automático Olympus, modêlo BH2. Foi utilizado filme Agfa Copex (ASA 25), para os negativos e papel Kodabromide F-3, para as ampliações.

Para o enquadramento taxonômico, seguiu-se o sistema de SIMONSEN (1979), exceto para o gênero Stauroneis, 
quando seguiu-se KRIGER (1954) apud HENDEY (1964).

\section{RESULTADOS}

Divisão: Chrysophyta

Classe: Bacillariophyceae

Ordem: Centrales

Subordem: Coscinodiscineae

Família: Thalassiosiraceae Lebour. emend. Hasle

Gênero: Aulacoseira Thwaites

Aulacoseira granulata (Ehrenberg) Simonsen Fig. 10

HUSTEDT, 1930:87, Fig.44 (como Melosira granulata (Ehr.)Ralfs.) Medidas: $12-20 \mu \mathrm{m}$ de altura; 5 - $6 \mu \mathrm{m}$ de diâmetro

Material examinado: FLOR 12.730; $12.732 ; 12.729,12.727 ; 12.725$.

Dados ecológicos: Cosmopolita, de água doce, planctônica, alcaliófila. (RODRIGUES, 1984)

Obs.: Citada para a Amazônia por UHERKOVICH et al. (1979) e por DE OLIVEIRA et al. (1992) como Melosira granulata (Ehr.) Ralfs.

Aulacoseira italica (Ehrenberg) Simonsen. Fig. 11

HUSTEDT, 1930:91, Fig.50 (como Melosira italica (Ehr.)Ralfs.) Medidas: $20-230 \mu \mathrm{m}$ de altura; $5 \mu \mathrm{m}$ de diâmetro.

Material examinado; FLOR 12.731.

Dados ecológicos: Cosmopolita de água doce; oligohalóbia indiferente, alcaliófila; Oligossapróbia. (RODRIGUES, 1984).

Ordem: Pennales

Subordem: Araphidineae

Família: Diatomaceae Dumortier

Gênero: Fragilaria Lyngbye

Fragilaria javanica Hustedt Fig. 31
SILVA, 1987:15, Est.1, Fig.7 a-i

Valvas lineares; margens retas ou com constricção mediana, em uma ou em ambas as margens; extremidades largo- capitadas, com ápices truncados ou ligeiramente arredondados; pseudorafe dificilmente visível, marcada pela interrupção das estrias na região mediana, que ficam ligeiramente desencontradas; espinhos presentes ou não, nas margens das valvas; estrias transapicais paralelas.

Medidas: 50-70 $\mu \mathrm{m}$ de comprimento; 4-5 $\mu \mathrm{m}$ de largura; $19-22$ estrias $/ 10 \mu \mathrm{m}$.

Material examinado : FLOR 12.733; $12.729 ; 12.728 ; 12.730$.

Dados ecológicos: de água doce, acidófila

Obs.: Citada para a Amazônia por DE OLIVEIRA et al. (1992).

Subordem: Raphidineae

Família: Eunotiaceae Kutzing Gênero: Actinella Lewis

Actinella brasiliensis Grunow Fig. 3 - 5

VAN HEURCK, 1881: Est.35, Fig.19

Valvas com polos desigualmente desenvolvidos. Polo superior mais alargado, sub-capitado, com a parte distal projetando-se como uma ponta afilada, ligeiramente voltada para o lado dorsal; polo inferior mais estreito, arredondado. Nódulos terminais bem desenvolvidos, próximos às extremidades; poros de mucilagem presentes nas extremidades; estrias transapicais paralelas, ligeiramente radiais na extremidade superior.

Medidas: $71-101,5 \mu \mathrm{m}$ de comprimento; 2,6-7,5 $\mu \mathrm{m}$ de largura (pólo mais largo); $4-5,5 \mu \mathrm{m}$ (pólo mais 
estreito); 17 estrias $/ 10 \mu \mathrm{m}$.

Material examinado: FLOR 12.732; $12.725 ; 12.728$.

Obs.: Citada para a Amazônia por UHERKOVICH et al. (1979) e DE OLIVEIRA et al. (1992)

Actinella guianensis Grunow Fig. 7 VAN HEURCK, 1881; Est.35, Fig.17 FRENGUELLI, 1933:435, pl.5, Fig.18-20

Valvas com polos desigualmente desenvolvidos. Polo superior mais alargado, sub-capitado com a parte distal projetando-se como uma ponta ligeiramente voltada para o lado dorsal; polo inferior mais estreito, entumescido próximo à extremidade; nódulos terminais bem desenvolvidos; poros de mucilagem presentes nas extremidades; estrias transapicais paralelas, ligeiramente radiais na extremidade superior; espinhos em ambas as margens, podendo aparecer como $p$ ontos, dependendo da posição da valva. Medidas: $62-25 \mu \mathrm{m}$ de comprimento; $14 \mu \mathrm{m}$ de largura (pólo mais largo); 5-8 $\mu \mathrm{m}$ (pólo mais estreito); $13-15$ estrias $/ 10 \mu \mathrm{m}$. Material examinado: FLOR 12.732; $12.725 ; 12.733$.

Dados ecológicos: De água doce e salobra, mucícola.

Obs.: Citada para a Amazônia por UHERKOVICH et al. (1979) e por DE OLIVEIRA et al. (1992).

Actinella mirabilis Grunow Fig. 6 VAN HEURCK, 1896:306, Fig.70 a-b VAN HEURCK, 1881:35, Fig.16 HUSTEDT, 1913 in SCHMIDT et al., taf. 292, Fig.1-4

Valvas arqueadas, com polos desigualmente desenvolvidos; sendo o superior mais largo.e o inferior levemente inflado. Margem dorsal com ondulações (geralmente 10).

Medidas: 75,5-275 $\mu \mathrm{m}$ de comprimento; 13-25 $\mu \mathrm{m}$ de largura; $10-11$ estrias $/ 10 \mu \mathrm{m}$. Material examinado: FLOR 12.729; 12.728 .

Dados ecológicos: Em água doce, acidófila.

Obs.: Citada para a Amazônia por UHERKOVICH et al. $(1979 ; 1980)$ e por DE OLIVEIRA et al. (1992).

Actinella robusta Hustedt. Fig. 1-2

HUSTEDT, 1952a:134, Fig.6

DE OLIVEIRA et al., 1992:519, Fig.7

Valvas encurvadas com polos desiguais, ligeiramente voltados para o lado dorsal, sendo o superior mais alargado, polo inferior mais estreito, arredondado; nódulos terminais bem desenvolvidos, próximo às extremidades; estrias transapicais paralelas.

Medidas: $110-220 \mu \mathrm{m}$ de comprimento; 5-8,7 $\mu \mathrm{m}$ de largura (pólo mais largo); 4,35-5 $\mu \mathrm{m}$ de largura (pólo mais estreito); 14 estrias $/ 10 \mu \mathrm{m}$.

Material examinado: FLOR 12.729; $12.728 ; 12.725$.

Dados ecológicos: Em água doce, epífita, ocasional no bentos (OLIVEIRA et al., 1992)

Obs.: Citada para a Amazônia por DE OLIVEIRA et al. (1992).

Gênero: Eunotia Ehrenberg

Eunotia cf. batavica A. Berg Fig. 8

A.BERG, 1939: 462, Fig.5-188

Valvas planas, com margens paralelas; apresentando no centro, uma depressão na face dorsal e uma saliência na face ventral; extremidades arredondadas estrias delicadas, regulares, paralelas, 
arqueadas nos ápices. Pseudo-rafe reduzida, correndo paralela a margem ventral. Rafe curta.

Medidas: $160-180 \mu \mathrm{m}$ de comprimento; 7,5-9 $\mu \mathrm{m}$ de largura; 14 estrias $/ 10 \mu \mathrm{m}$.

Material examinado: FLOR 12.730; 12.725 .

Obs.:É semelhante à E.batavica diferindo apenas nas medidas.Os exemplares identificados sào maiores no comprimento, motivo pelo qual optamos por deixá-lo em "confer".

Eunotia camelus Ehrenberg Fig. 9 DE OLIVEIRA et al., 1992:521, Fig.62 SILVA, 1987:22, Est.I, Fig.11

Valvas arqueadas; margem ventral côncava; margem dorsal convexa, com duas ondulações; extremidades arredondadas, voltadas para a margem dorsal; nódulos terminais evidentes, próximos às extremidades valvares.

Medidas: $25-30 \mu \mathrm{m}$ de comprimento; 7,5-8 $\mu \mathrm{m}$ de largura; 18 estrias $/ 10 \mu \mathrm{m}$. Material examinado: FLOR 12.730.

Dados ecológicos: Em água doce, em regiòes tropicais e subtropicais. Pouco conhecida em suas características ecológicas (LUCHINI et al., 1972).

Comentários: Os exemplares analisados assemelham-se à E. camelus Ehr. em PATRICK (1940a) e SILVA(1978), porém, têm as estrias transapicais nítidamente pontuadas ao longo das valvas.

Obs.: Citada para a Amazônia por DE OLIVEIRA et al. (1992).

Eunotia diodon Ehrenberg. Fig. 16 KRAMMER \& LANGEBERTALOT, 1991:191, Fig. 149:8-19

FOGED, 1977:54, pl.IX, Fig. 1

A.BERG, 1939:458, Fig.4-170

CLEVE-EULER, 1953: 128, Fig.468c.
Valvas arqueadas; margem ventral quase reta à côncava; margem dorsal convexa com duas ondulações; extremidades estreitas, rômbicas à fortemente arredondadas .Estrias transapicais paralelas, tornando-se radiais e encurvadas do centro para as extremidades. Nódulos polares nas extremidades da valva.

Medidas: 32-69 $\mu \mathrm{m}$ de comprimento; $8-13$ $\mu \mathrm{m}$ de largura; $13-18$ estrias $/ 10 \mu \mathrm{m}$.

Material examinado: FLOR 12.725; 12.729 .

Dados ecológicos: Em água doce à alcalina (FOGED, 1977).

Eunotia cf. glacialis Meister Fig. $14-15$

KRAMMER \& LANGEBERTALOT, 1991:207, Fig.,151:1-10A.

Valvas com margens geralmente paralelas; margem ventral côncava, margem dorsal convexa; terminações arredondadas a capitadas; levemente reflexas. Nódulos terminais grandes, na margem ventral, próximos aos ápices.

Medidas: $88-92 \mu \mathrm{m}$ de comprimento; 3,1$4 \mu \mathrm{m}$ de largura; $13-15$ estrias $/ 10 \mu \mathrm{m}$.

Material examinado: FLOR 12.728; $12.725 ; 12.731$.

Dados ecológicos: Em água doce, frias e ácidas; epífita, epilítica.

Comentários: Os exemplares por nós examinados apresentaram ora as margens retas, paralelas, ora uma leve gibosidade no centro da margem dorsal ; são muito semelhantes a $E$. grunowii Berg f., descrita e ilustrada em A.BERG (1939), p.437 fig.2:77, no entanto diferem desta pela direção das estrias. Os exemplares estudados assemelham-se à ilustração de 
UHERKOVICH et al. (1979); tab.7, fig. 12 como E. sp. (E. alpina (Naeg.) Hust. forma?, E. lunaris (Ehr.) Grun.forma?) faltando, no entanto, as medidas. Difere de E. naegeli Migula var, naegeli Migula descrita e ilustrada em PATRICK et al. (1966:190), pr.10, fig. 6 por apresentar medidas maiores, principalmente quanto à largura. É semelhante a $E$. glacialis descrita e ilustrada em KRAMMER \& LANGEBERTALOT (1991): opus, cit. inclusive quanto às medidas, este autor sinonimiza alguns táxons, dentre estes, E. grunowii "pro parte". Segundo este mesmo autor, "E. glacile Ehr.; E. glacialis e $E$. valida, provavelmente são sinônimos, valendo o nome $E$ glacialis Meister enquanto não se encontrar o sinônimo mais antigo".

Eunotia lineolata Hustedt. Fig. 22 - 23

SILVA, 1987:31, Est.3, Fig.18 a-e

FRENGUELLI, 1933:436, Est.6, Fig.2-3 (como Desmogonium guyanense Ehr.).

Valvas levemente arqueadas, alongadas, com margens paralelas entre si; extremidades arredondadas, com as mesmas dimensões do corpo maior da valva, até capitadas, em forma de cunha, com o ápice truncado; nódulos terminais nítidos, junto às extremidades da valva; rafe visível ; poros de mucilagem nas duas extremidades; pseudorafe paralela à margem ventral; estrias transapicais paralelas, radiais nas extremidades; espinhos delicados em ambas as margens, podendo aparecer como pontos, dependendo da posição da frústula.

Medidas: 65-174 $\mu$ m de comprimento; 4 $35,6 \mu \mathrm{m}$ de largura; $15-26$ estrias $/ 10 \mu \mathrm{m}$.
Material examinado: FLOR 12.732; $12.731 ; 12.730 ; 12.725$.

Dados ecológicos: De água doce, correntes e estagnadas (FRENGUELLI, 1933). Geralmente em regiôes tropicais (KUCHINI et al., 1972).

Obs.: Citada para a Amazônia por DE OLIVEIRA et al. (1992).

Eunotia lunaris (Ehrenberg) Brebisson.

FRENGUELLI, 1933: 437, Est.6, Fig.11-12

VAN HEURCK, 1881: Est.35, Fig.3-4 (como E .lunaris (Ehr.) Grun.). SILVA, 1987:32, Est.3, Fig. 22

Valvas ligeiramente arqueadas; margens paralelas ou margem ventral levemente côncava e dorsal levemente convexa; extremidades arredondadas, voltadas para o lado dorsal; nódulos terminais evidentes, próximos às extremidades da valva; rafe não visível; estrias transapicais paralelas.

Medidas: $28-80 \mu \mathrm{m}$ de comprimento; $2,5-$ $4 \mu \mathrm{m}$ de largura; $15-20$ estrias $/ 10 \mu \mathrm{m}$.

Material examinado: FLOR 12.730.

Dados ecológicos: Água doce, ambientes lóticos e lênticos, planctônica (TORGAN et al., 1991). Acidófila.

Eunotia patrickae Hustedt. Fig. 24 HUSTEDT, 1965:394, Fig.17-18 PATRICK, 1940:4, Fig.9 (como E. attenuata Patr.)

Valvas longas e estreitas, margem dorsal levemente convexa, margem ventral levemente côncava; margens paralelas estreitando muito nas extremidades; ápices ligeiramente voltados para a margem dorsal. Nódulos terminais inconspícuos.

Medidas: 95-116 $\mu \mathrm{m}$ de comprimento; 2,5-5 $\mu \mathrm{m}$ de largura; 11-12 estrias $/ 10 \mu \mathrm{m}$. 
Material examinado: FLOR 12.730.

Comentários: Descrita por PATRICK (1940) como E. attenuata, HUSTEDT (1965) comenta que deu o nome de $E$. patrickae pois a primeira já existia como E (lunaris var.?) attenuata Cleve (1900,s.277,fig.19) e E. attenuata A.Cleve Euler (1934, S.17, fig.6). HUSTEDT (op. cit) comenta que $E$. attenuata Mang. provavelmente é $E$. monodon Ehr. VANLANDINGHAM (1969) reconhece como válida $E$. attenuata Cleve-Euler (1934, p.17, fig.6) e invalida E. attenuata. Patrick (1940), p. 4 , fig. 9 chamando-a de E. exepta VanLan. e invalida E. attenuata Mang., chamando-a de E.triconfusa VanLan., sem fazer referencia a HUSTEDT (1965). Dados ecológicos: De água doce; Em regiões tropicais.

Obs.: Citada Para a Amazônia por PATRICK (1940).

Eunotia (trigibba Hustedt. var.) paucistriata Hustedt. Fig. 28

SILVA, 1987:37, Est. 4, Fig. 26 a-b

CLEVE-EULER, 1953:105, Fig. 437 h-m (como E.trigiba Hust.var. genuina Cleve-Euler).

Valvas ligeiramente arqueadas, com margem ventral fortemente côncava; margem dorsal com tres ondulações de igual tamanho; extremidades arredondadas, com aproximadamente a metade da largura máxima da valva; nódulos terminais pequenos; rafe visivel; pseudorafe quase paralela e bem próxima à margem ventral; estrias transapicais paralelas, com espaçamento irregular entre elas e estrias incompletas entre as normais; estrias ligeiramente radiais e mais próximas entre si nas extremidades.

Medidas: $34-62 \mu \mathrm{m}$ de comprimento; $10-$ $18,25 \mu \mathrm{m}$ de largura; $10-13$ estrias $/ 10 \mu \mathrm{m}$. Material examinado: FLOR 12.727; 12.728 .

Dados ecológicos: de águas doces, ambientes lênticos, encontrada no plâncton. (TORGAN et al., 1991 para $E$. trigibba Hust).

Eunotia pectinalis (Dill.?) Rabh. var. pectinalis Fig. 19 - 20

SILVA, 1987:39, Est..4, Fig. 28

PATRICK \& REIMER, 1966: 204, pl.12, Fig. 10

Valvas ligeiramente arqueadas, com margens ventrais ligeiramente côncavas; margens dorsais um pouco convexas, com tres ou mais ondulações; extremidades atenuado-arredondadas, levemente voltadas para a margem dorsal; nódulos terminais nítidos, nas extremidades da valva; rafe não evidente; área hialina visível, nas extremidades, próxima à margem ventral; estrias transapicais paralelas.

Medidas: $37,5-72 \mu \mathrm{m}$ de comprimento; 5-8 $\mu \mathrm{m}$ de largura; $15-16$ estrias $/ 10 \mu \mathrm{m}$. Material examinado: FLOR 12.730.

Dados ecológicos: Cosmopolita de águas doce, oligosapróbia, acidófila, também em águas alcalinas; oligotrófica a eutrófica. (LUCHINI et al., 1972).

Obs.: Citada para a Amazônia por UHERCKOVICH et al, (1980).

Eunotia pectinalis var. minor (Kutzing) Rabenhorst Fig. 17 - 18 - 21

PATRICK \& REIMER, 1966: 207, pl.12, Fig. 13

KRAMMER \& LANGE-BERTALOT, 
1991: Fig. 143:4-9A (como E. implicata Nörpel)

Margem ventral levemente côncava. Margem dorsal distintamente convexa, algumas vezes com duas ondulações pouco profundas. Valvas mais estreitas nas extremidades do que no centro. Ápices da valva arredondados; algumas vezes estreitado mas nunca muito diferente do resto do corpo da valva. Nódulos terminais distintos, próximos às extremidades ,Estrias transapicais perpendiculares a margem ventral e encurvadas nos ápices.

Medidas: 44-45,6 $\mu \mathrm{m}$ de comprimento; $7,2-9 \mu \mathrm{m}$ de largura; $15-16$ estrias $10 \mu \mathrm{m}$. Material examinado: FLOR 12.730.

Dados ecológicos: Em águas ácidas a neutras. De água doce, oligohalóbia, rupicola, cosmopolita. (RODRIGUES (1984). Comentários: No material estudado são identificados os exemplares, aqui ilustrados pelas figuras 17 e 18 denominados por KRAMMER \& LANGE-BERTALOT (1991) E. implicata Nörpel. (Fig. 143:4-9A),

Neste trabalho aceitamos a interpretação de PATRICK \& REIMER (1966).

Obs.: Citada para a Amazônia por UHERKOVICH et al. (1980) e DE OLIVEIRA et al. (1992).

Eunotia serra Ehrenberg Fig.27

UHERKOVICH et al., 1979: tomo VIII, Fig.5

PATRICK \& REIMER, 1966: 200, pl.12, Fig.2

Valvas alongadas, arqueadas; margem ventral levemente côncava; margem dorsal convexa e com número variável de ondulações, iguais entre si; extremidades arredondadas e voltadas para a margem dorsal; nódulos terminais evidentes, próximos às extremidades da valva; estrias transapicais paralelas, legeiramente radiais nas extremidades.

Medidas: $50-87 \mu \mathrm{m}$ de comprimento; $11-15 \mu \mathrm{m}$ de largura; $8-10$ estrias/10 $\mu \mathrm{m}$. Material examinado: FLOR 12.729; $12.733 ; 12.730 ; 12.732 ; 12.725$; $12.728 ; 12.726$.

Dados ecológicos: De água doce, oligohalóbia. (LUCHINI et al., 1972). Obs.: Citada para a Amazônia por UHERKOVICH et al. (1979) e DE OLIVEIRA et al. (1992).

Eunotia serra var. diadema Ehrenberg) Patrick. Fig. 25-26

CLEVE-ULER ,1953:125, Fig.464 a FOGED, 1977:59, pl. VIII, Fig.18 (como E.robusta Ralfs var.tetraodon (Ehr.) Ralfs.)

PATRICK \& REIMER, 1966:201, pl.12, Fig. 3

Valvas com a margem ventral côncava, margem dorsal fortemente convexa, com quatro ou mais ondulações, terminações das valvas protraidas. Nódulos terminais na margem ventral da valva. Estrias distintamente pontuadas, radiadas. Presença de algumas estrias curtas na margem dorsal que não atingem toda a largura da valva.

Medidas: 50-71 $\mu \mathrm{m}$ de comprimento; $17-$ $22 \mu \mathrm{m}$ de largura; $14-15$ estrias $/ 10 \mu \mathrm{m}$.

Material examinado: FLOR 12.729; $12.734 ; 12.730 ; 12.725$.

Comentários: KRAMMER \& LANGEBERTALOT (1991) distinguem E. serra var. diadema de $E$. serra var. tetraodon. A primeira teria 6 onduções e a segunda apenas 4. PATRICK (1958) descreve $E$. serra var. diadema como possuindo 4 ou 
mais ondulações; mais tipicamente 4, citando $E$. tetraodon como sinônimo.

Dados ecológicos: Em águas de $\mathrm{pH}$ extremamente ácido $(4,5)$; em águas oligotrófica à distrófica. (PATRICK et al.,1966).

Obs.: Citada para a Amazônia por UHERKOVICH et al. (1979) e (1980) (como E. diadema Ehr. var. tetraodon (Ehr.) Cl.) e por DE OLIVEIRA et al. (1992).

Eunotia vanheurckii Patrick var. vanheurckii. Fig. 29

PATRICK \& REIMER, 1966:210, Est. 13, Fig.7

PATRICK, 1958:12, Fig.12

SILVA, 1987:48, est.5, Fig.39

Valvas com margens ventrais retas $\mathrm{e}$ paredes com engrossamentos na região mediana; margem dorsal fortemente convexa; extremidades arredondadas, formadas pelo estreitamento gradual da valva; nódulos terminais nítidos, próximos às extremidades da valva; rafe não evidenciável; estrias transapicais paralelas, mais próximas entre si nas extremidades. Medidas: 13-26,5 $\mu \mathrm{m}$ de comprimento; 5 $8,5 \mu \mathrm{m}$ de largura; $10-16$ estrias $/ 10 \mu \mathrm{m}$. Material examinado: FLOR 12.729.

Dados ecológicos: Em água doce; turfas, lagos e charcos. As vezes em águas distróficas (LUCHINI et al., 1972).

\section{Eunotia sp.1 Fig.12 - 13}

Valvas com margens paralelas, extremidades arredondadas à obtusoarredondadas. Nódulos terminais grandes; próximos às extremidades da valva; rafe não evidente; poro de mucilagem em ambas as extremidades; pseudo-rafe paralela à margem ventral; estrias transapicais paralelas.

Medidas: $131,2-320 \mu \mathrm{m}$ de comprimento; 5-10 $\mu \mathrm{m}$ de largura; $10-$ 13 estrias $/ 10 \mu \mathrm{m}$.

Material examinado: FLOR 12.730; $12.733 ; 12.732 ; 12.725 ; 12.728$.

Obs.: Assemelha-se a E. baculus Hust. (HUSTEDT, 1965:394, Fig.19-20) porém não apresenta a "fina banda hialina nitidamente pontuada" na margem ventral.

Eunotia sp.2 Fig. 30

SILVA, 1987:53; Est.5, Fig. 46

Valvas fortemente arqueadas no centro e retas nas extremidades; margem ventral côncava; margem dorsal convexa; nódulos terminais nas extremidades da valva; rafe não evidente; área hialina próxima à margem ventral; estrias transapicais pontuadas paralelas entre si.

Medidas: $27 \mu \mathrm{m}$ de comprimento; 5,8 $6 \mu \mathrm{m}$ de largura; 12 estrias $/ 10 \mu \mathrm{m}$.

Material examinado: FLOR 12.725.

Família: Naviculaceae Kutzing Gênero: Anomoeoneis Kutzing Anomoeoneis serians (Brebisson ex Kutzing) Cleve

FOGED, 1971:276, pl.IX, Fig.17

PATRICK \& REIMER, 1966: 378, pl.33, Fig.1

Valvas rômbico-lanceoladas; extremidades atenuado-arredondadas; área axial estreita, reta; área central rômbica; rafe filiforme, reta; estrias transapicais radiais no centro, interrompidas por áreas hialinas onduladas longitudinais.

Medidas: $31 \mu \mathrm{m}$ de comprimento; 7 $\mu \mathrm{m}$ de largura. 
Material examinado: FLOR 12.730; $12.732 ; 12.731 ; 12.727 ; 12.725 ; 12.728$.

Dados ecológicos: Em água doce, litoral, rupicola, muscícola, halófoba, acidófila (MOREIRA FILHO et al., 1985). Epilítica, oligohalóbia, oligotrófica (RODRIGUES, 1984).

\section{Gênero Capartogramma Kufferath}

Capartogramma crucicula (Grunow ex Cleve) Ross

PATRICK \& REIMER, 1966:372, pl.30, Fig.16.

Valvas eliptico-lanceoladas; extremidades rostradas, pseudo-septo próximo às extremidades; área axial estreita, linear; área central com estauro em forma de "xis"; rafe filiforme, reta, estrias transapicais radiais.

Medidas: $28 \mu \mathrm{m}$ de conprimento; 8,8 $\mu \mathrm{m}$ de largura.

Material examinado: FLOR 12.730; $12.732 ; 12.725$.

Dados ecológicos: De águas doces, ambientes lóticos e lênticos, encontrada no plâncton. (TORGAN et al., 1991).

Gênero: Frustulia Rabenhorst

Frustulia rhomboides (Ehernberg) De Toni var. rhomboides Fig. 32

PATRICK \& REIMER, 1966: 308, pl. 21, Fig.7

SILVA, 1987:73, Est.7, Fig.65

Valvas rômbico-lanceoladas, com extremidades atenuadoarredondadas; área axial com duas costelas retas e paralelas; rafe filiforme, reta, entre as costelas; nódulo central constrito na região mediana; nódulos terminais alargados; prolongando-se através de extremidades mais afiladas; estrias transapicais paralelas na região mediana e radiais em torno dos nódulos terminais; estrias longitudinais paralelas, tortuosas na região mediana. Medidas: $68,5-12 \mu \mathrm{m}$ de comprimento; $12,5-30 \mu \mathrm{m}$ de largura; $24-30$ estrias transapicais $/ 10 \mu \mathrm{m}$.

Material examinado: FLOR 12.733; $12.732 ; 12.731 ; 12.729 ; 12.727$; $12.725 ; 12.726 ; 12.728 ; 12.730$.

Dados ecológicos: Em água doce. Comum em lagos e pântanos com águas levemente ácidas. Nos trópicos, em águas alcalinas. Oligohalóbia? (LUCHINI et al., 1972).

Obs.: Citada para a Amazônia por DE OLIVEIRA et al. (1992) e UHERKOVICH et al. $(1979 ; 1980)$.

Gênero: Gomphonema Ehrenberg Gomphonema augur Ehrenberg var.turris (Ehrenberg) Lange-Bertalot. Fig. 33

CALLEGARO et al.,1993:101, Fig.56 KRAMMER \& LANGE-BERTALOT, 1986:363, Est.158, Fig.2-5

GERMAIN,1981:301, pl.11, Fig.1 (como G.acuminatum Ehr.var.turris (Ehr.) $\mathrm{Cl}$.

Valvas claviformes, metade superior levemente ondulada com extremidade cuneada a levemente apiculada; margens côncavas em direção à extremidade inferior com extremidade arredondada. Área axial estreita, nitida; área central alargada arredondada, com um estigma isolado. Estrias radiadas, nítidamente pontuadas. Rafe ligeiramente sinuosa.

Medidas: 74,4-90 $\mu \mathrm{m}$ de comprimento; $15,4-19 \mu \mathrm{m}$ de largura; 8-9 estrias $/ 10 \mu \mathrm{m}$. Material examinado: FLOR 12.730; 12.725 .

Dados ecológicos: Em água doce; 
litoral, em águas correntes e estancadas. (LUCHINI et al. 1972).

Gomphonema gracile Ehrenberg Fig. 35-36 KRAMMER \& LANGE - BERTALOT, 1986: 361, Fig. 156: 1-11, Fig. 154: 26,27 GERMAIN,1981:310, pl.115, Fig.1-14

Valvas lanceoladas, assimétricas em relação ao eixo apical; extremidades agudas; área axial estreita, reta; área central pequena, unilateralmente mais desenvolvida pelo encurtamento da estria mediana; do outro lado apresenta um estigma isolado. Rafe filiforme, reta; estrias levemente radiadas, distintamente pontuadas.

Medidas: 90-100 $\mu \mathrm{m}$ de comprimento; 8-14 $\mu \mathrm{m}$ de largura; 14 estrias $/ 10 \mu \mathrm{m}$. Material examinado: FLOR 12.728.

Dados ecológicos: Prefere águas ácidas (GERMAIN, 1981); De água doce, tolera grandes variações de $\mathrm{pH}$ e condutividade. (PATRICK et al., 1975); Oligohalóbia, oligossapróbia, litoral, (MOREIRA FILHO et al., 1993).

Comentários: Segundo PATRICK et al. (1975) é um táxon muito variável tanto no comprimento quanto no número de estrias.

Gomphonema parvulum (Kutzing) Kutzing

PATRICK \& REIMER, 1975: 123, pl.17, Fig.7-8

SILVA, 1987:82, Est.7, Fig.74 a-d

Valvas lanceoladas a clavadolanceolada, extremidades superiores rostradas e inferiores agudas, atenuado arredondadas a rostradas; área axial estreita, reta; área central pequena, unilateral, formada pelo encurtamento da estria mediana; estria mediana oposta à área central, terminando por um ponto isolado; rafe filiforme, reta; estrias transapicais paralelas na região mediana e ligeiramente radiais nas extremidades.

Medidas: $35-45 \mu \mathrm{m}$ de comprimento; 7,5$10 \mu \mathrm{m}$ de largura; 9-13 estrias $/ 10 \mu \mathrm{m}$.

Material examinado: FLOR 12.733; $12.730 ; 12.732 ; 12.731 ; 12.727 ; 12.725$. Dados ecológicos: Cosmopolita de água doce, oligohalóbia, indiferente, $\mathrm{pH}$ indiferente, mesossapróbia, litoral, epífita. (RODRIGUES, 1984).

Gomphonema subtile Ehrenberg Fig, 34 FRICKE, 1902 in A.SCHMIDT, pl.236, Fig. $13-14$

UHERKOVICH et al., 1979: tf. VII, fig.14 (como G. subtile Ehr.var. sagitta (Schum.) Cl. f.).

CLEVE-EULER, 1955:177, Fig.1268d (como G.subtile (Schum.) Grun.).

Valvas levemente infladas no centro, estreitando em direção às extremidades. Ápice inflado, em forma de cunha. Área axial distinta, alargando na porção mediana da valva. Área central de um lado mais ampla pela ausência de estrias; no outro lado estrias medianas, terminando em um estigma isolado. Rafe filiforme, reta; estrias radiadas, distintamente pontuadas.

Medidas: $90 \mu \mathrm{m}$ de comprimento; 10 $\mu \mathrm{m}$ de largura; 12 estrias $/ 10 \mu \mathrm{m}$.

Material examinado: FLOR 12.731.

Dados ecológicos: De água doce, prefere águas quentes com baixa condutividade (PATRICK et al., 1966). Muito sensível à poluição. (KRAMMER \& LANGE BERTALOT, 1986).

Comentários: Os exemplares por nós analisados possuem as medidas maiores do que as citadas na literatura. Obs.: Citado para a Amazônia por 


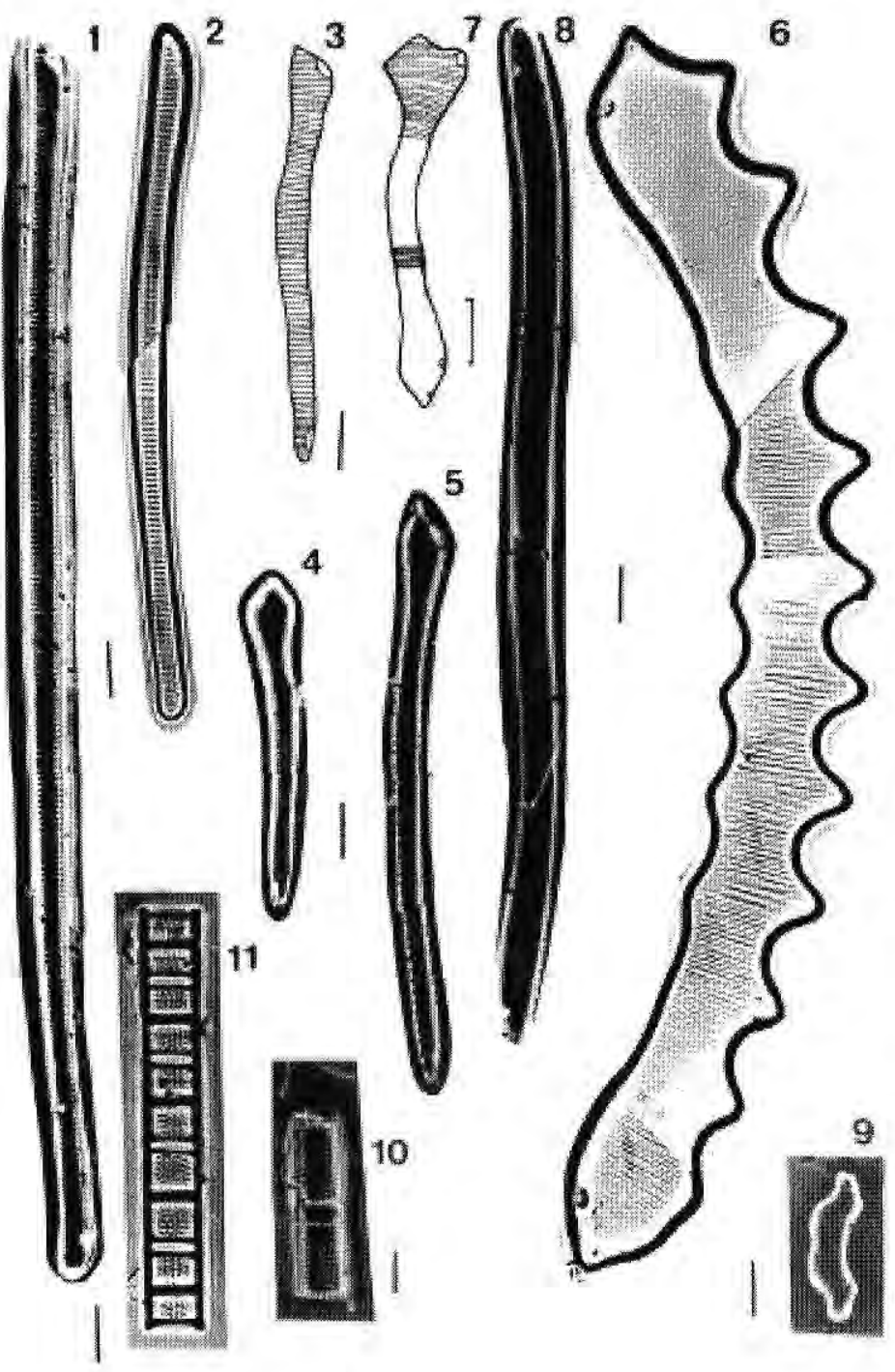

Fig. 1-2 - Actinella robusta Hust.

Fig. 3-5 - Actinella brasiliensis Grun.

Fig. 6 - Actinella mirabilis Grun.

Fig. 7 - Actinella guianensis Grun.

Fig. 8 - Eunotia "cf" batavica $\mathrm{f}$ B.

Fig. 9 - Eunotia camelus Ehr.

Fig. 10 - Autacoseira granulata (Ehr.) Simonsen.

Fig. 11 - Aulacoseira italica (Ehr.) Simonsen. 


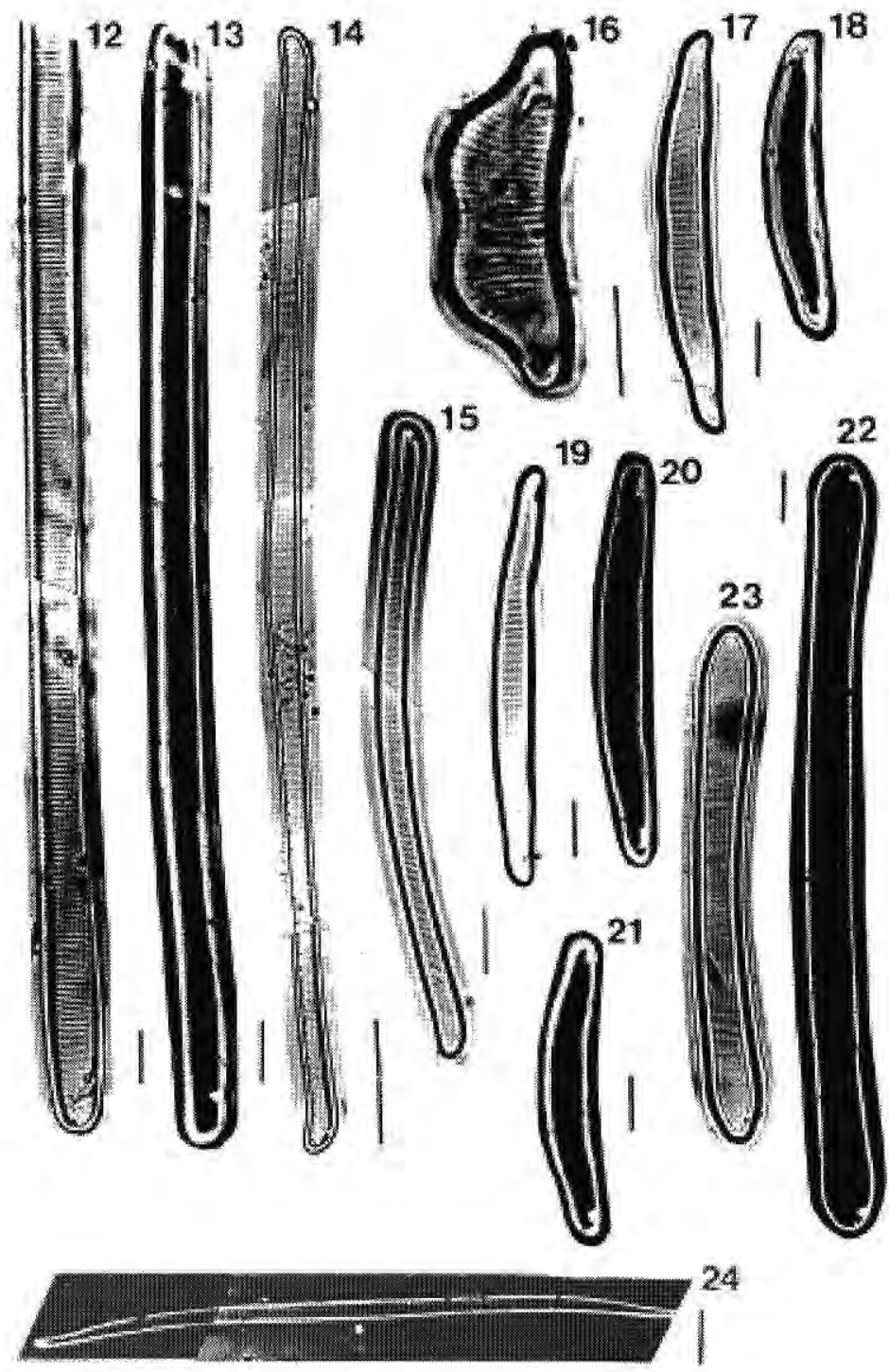

Fig, 12-13 - Eumotia sp.1

Fig. 14-15 - Eunotia "cf" glacialis Meister.

Fig. 16 - Eunotia diodon Ehr.

Fig. 17-18 - Eunotia pectinalis (Dill ?) Rabh. var. minor (Kutz.) Rabh.

Fig. 19-20 - Eunotia pecrinalis (Dill ?) Rabh.

Fig. 21 - Eunotia pectinalis var, minor (Kutz.) Rabh,

Fig. 22-23 - Eunotia lineolata Hust.

Fig. 24 - Eunotia Patrickae Hust. 


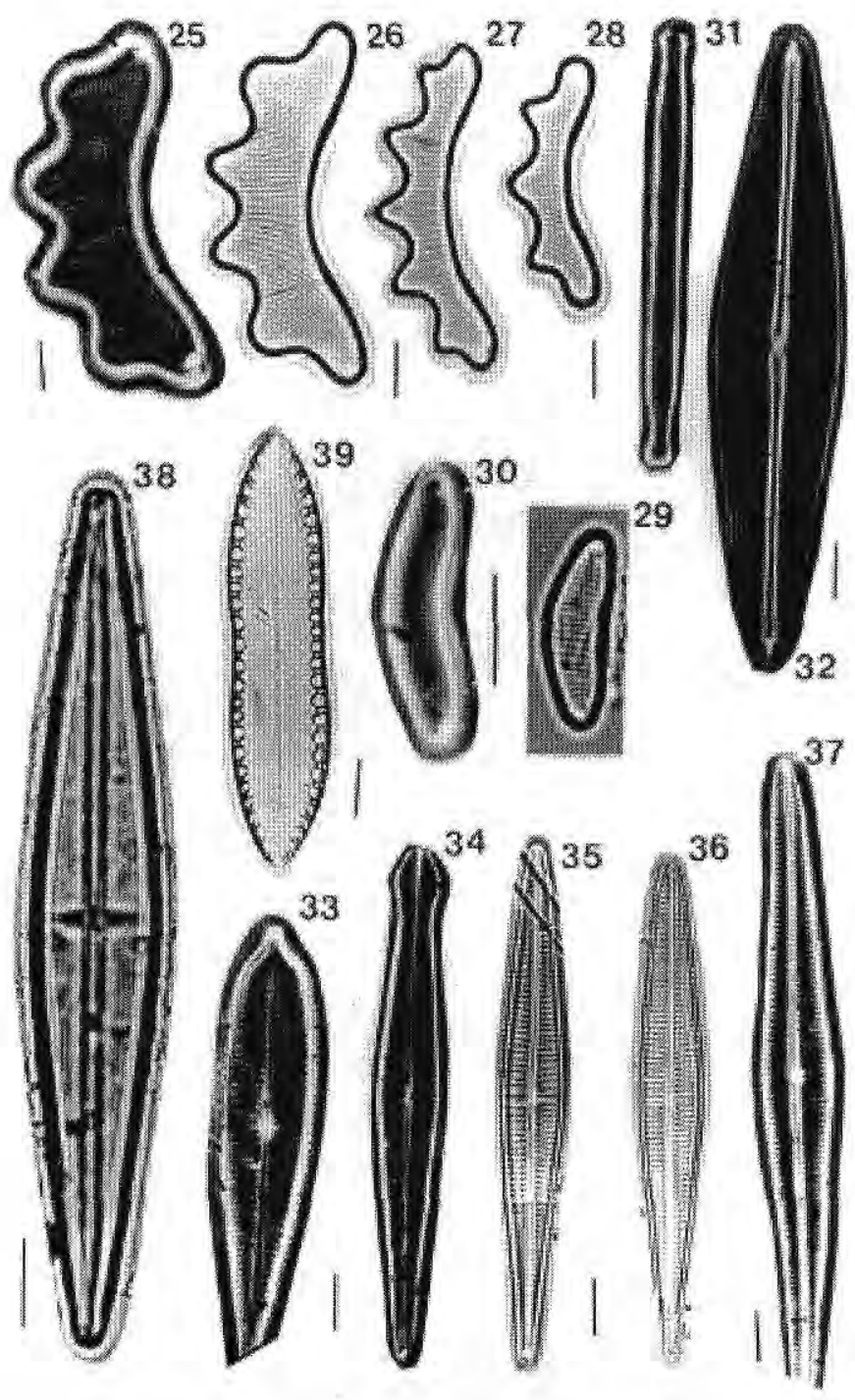

Fig. 25-26 - Euhotia serra (Ehr.) var. diadema (Ehr.) Patrick.

Fig. 27 - Eunotia serra Ehr.

Fig. 28 - Eunotia (trigibba Hust, var.) paucistriata Hust.

Fig. 29 - Eunotia vanheurckii Patrick var. vanheurkii

Fig. 30 - Eunotia sp. 2

Fig. 31 - Fragilaria javanica Hust.

Fig. 32 - Frustulia rhomboides (Ehr.) De Toni.

Fig. 33 - Gomphonema angu Ehr. var, turris (Ehr.) Lange-Bertalot

Fig. 34 - Gomphonema subtile Ehr.

Fig. 35-36 - Gomphonema gracile Ehr.

Fig. 37 - Gomphonema sp.

Fig. 38 - Stauroneis phoenicenteron (Nitz.)Ehr.

Fig. 39 - Surirella bisserialu Breb. var constricta Hust. 
UHERKOVICH et al. (1979)

Gomphonema sp. Fig. 37

Valvas linear-lanceoladas, alargadas na parte mediana, extremidades subagudas, arredondadas. Área axial muito estreita; área central pequena, arredonda, com um estígma em um lado. Rafe reta.Estrias paralelas, finamente pontuadas, levemente radiadas.

Medidas: $107,3 \mu \mathrm{m}$ de comprimento; 8 $16,6 \mu \mathrm{m}$ de largura; 14 estrias $/ 10 \mu \mathrm{m}$.

Material examinado: FLOR 12.728.

Gênero: Stauroneis Ehrenberg.

Stauroneis phoenicenteron (Nitzsch) Ehrenberg. Fig. 38

PATRICK \& REIMER; 1966: 359, pl,29, Fig. 3-4

Valvas lanceoladas; extremidades sub-rostradas, arredondadas; área axial linear; área central com estauro alargando-se ligeiramente em direção às margens e limitado por uma fileira de pontuações grosseiras; rafe reta, extremidades distais da rafe bifurcadas, com o ramo maior em forma de gancho; estrias transapicais radiais, nitidamente pontuadas.

Medidas: 75-200 $\mu \mathrm{m}$ de comprimento; $16-32 \mu \mathrm{m}$ de largura; $12-15$ estrias $/ 10 \mu \mathrm{m}$. Material examinado: FLOR 12.730; $12.732 ; 12.725$.

Dados ecológicos: Cosmopolita de água doce e salobra, litoral, oligohalóbia indiferente, Mesossapróbia (RODRIGUES, 1984).

Família: Surirellaceae Kutzing.

Gênero: Surirella Turpin

Surirella bisseriata Brebisson var. constricta Hustedt Fig. 39

SILVA, 1987:139, Est.14, Fig.135
Frústulas com eixo apical isopolar; valvas linear-elípticas, constrictas na região central; extremidades cuneadas; linha ondulada a um quarto da distância entre a região central e a margem valvar; área axial estreita; alvéolos transapicais bem marcados, radiais nas extremidades.

Medidas: $80-186 \mu \mathrm{m} ; 20-44 \mu \mathrm{m}$ de largura; 15 costelas $/ 100 \mu \mathrm{m}$.

Material examinado: FLOR 12.729.

Dados ecológicos: Em água doce, litoral e planctônica (LUCHINI et al., 1972).

\section{DISCUSSÃO}

Foram identificados 32 táxons específicos e infraespecíficos, distribuídos em 10 gêneros e 5 famílias. Eunotiaceae foi a familia melhor representada, com $50 \%$ dos táxons inventariádos, seguida de Naviculaceae com $25 \%$.

O gênero Eunotia se destacou dentre os demais, com 16 táxons.

Dois táxons pertencentes a Eunotia e um a Gomphonema num total de 3 táxons, não foram identificados a nível especifico, com a bibliografia disponivel.

Os táxons Eunotia cf. batavica e Eunotia cf. glacialis Meister foram mantidos em "confer", por não se ter uma grau de certeza suficiente para uma identificação definitiva. PATRICK \& REIMER (1966) comentam que muitas espécies de Eunotia podem ser encontradas numa faixa de $\mathrm{pH}$ entre 3,5 a 6. Segundo estes autores, as espécies de Actinella, são geralmente de águas ácidas e o gênero Desmogonium (neste trabalho, considerado dentro de Eunotia) é de águas fortemente ácidas. A única espécie de Fragilaria 
encontrada ( $F$. javanica Hust.) segundo HUSTEDT (1965) é de águas ácidas. Pela presença, principalmente, de Actinella, Eunotia e Fragilaria no conteúdo estomacal de Myleus sp. pode-se caracterizar as águas onde eles estiveram se alimentando em águas tropicais, oligotróficas e ácidas.

\section{AGRADECIMENTOS:}

Aos professores do Dept ${ }^{\circ}$ de Biologia da UFSC, Kay Saafeld pela tradução do alemão, e Carlos Fernando Miguez pelo empréstimo do fotomicroscópio.

\section{Bibliografia Citada}

BERG, A. 1939. Some new species and forms of the Diatom genus Eunotia Ehr. 1837. Botaniska Notiser, Lund. 123-462.

CALLEGARO, V.L.M.; SILVA, K.R.L.M.; SALOMONI, S.E. 1993, Flórula diatomológica de ambientes lênticos e lóticos do Parque Florestal do Turvo, Rio Grande do Sul, Brasil. Iheringia, ser. Bot., Porto Alegre, (43) :1-136.

CLEVE-EULER, A. 1951-1955. Die Diatomeen von Schweden und Finnland. K. Svenska Vetenskapsakad. Handl, Stockholm, 2 (1) :1-163;3 (3):1-153; 4 (1): $1-158 ; 4$ (5):1- 225; 5 (4):1-232.

DE OLIVEIRA, P.E.; STEINITZ-KANNAN, M. 1992. The diatom flora (Bacillariophyceae) of the Cuyabeno Faunistic Reserve, Equadorian Amazonia. Nova Hedwigia, Sturtgat. 54 (3-4):515-552.

FOGED, N. 1971. Freshwater diatoms in Thailand. Nova Hedwigia, Lehre. 22:267369.

FOGED, N. 1977. Freshwater Diatoms in Ireland. Bibl,Phycol, Vaduz, 34:1-221.

FRENGUELLI, J. 1933 A. Diatoméeas de la región de los esteros del Ybera(en la provincia de Corrientes). An. Mus. Argent.Cienc. Nat., Buenos Aires. (37):
365-475, est.1-9.

GERMAIN, H. 1981. Flore des diatomées:eaux douce et saumâtres. Paris.Ed.Boubée.44p.

HENDEY, N.I.1964. Bacillariophyceae (Diatoms).In: An introductory account of the smaller algae of british coastal waters, London, Her Magesty's Stationery Office. $317 \mathrm{p}$.

HUSTEDT, F. 1930. Bacillariophyta (Diatomeae). Jena,Gustav Fischer, 1930.446p. (Die Susswasser-Flora Mittleuropas,10).

HUSTEDT, F. 1952a. Neue und wenig bekannte Diatomeen. III. Phylogenetische Variationen bei den rhaphidioiden Diatomeen Ber. Deutsch.Bot.Ges. 65(5):133-144.

HUSTEDT, F. 1952b. Neue und wenig bekannte Diatomeen IV. Botan. Notis .4:966-410.

HUSTEDT, F. 1965. Neue und wenig bekannte Diatomeen. IX. Sus swasserdiatomeen aus Brasilien, insbesondere des Amazonasgebietes. Int. Rev. Ges. Hydrobiol, 50: 391-410.

KRAMMER, K, LANGE BERTALOT, H. 1986-1988. Bacillariophyceae .In: PASCHER,A. Susswasserflora von Mitteleuropa. Stuttgart, Gustav Fischer. KRAMMER, K; LANGE-BERTALOT, H. 1991. Bacillariophyceae. Teil. 3: Centrales, Fragilariaceae, Eunotiaceae In PASCHER,A Susswasserflora von Mitteleuropa. Stuttgart, Gustav Fischer. 166taf.,2180 fig.

KRAMMER, K.\& LANGE BERTALOT, H. 1991. Bacillariophyceae. Teil. 4. Susswasserflora von mitteleuropa. Stuttgart, Gustav Fischer. 88taf. 2048 fig.

KRIEGER, W. 1954. Chrysophyta. In: ENGLER,A. Syllabus der Pflanzenfamilien.12 ed.Berlin, Gebrüder Borntraeger.,(1):7:73-85.

LUCHINI, L.; VERONA, C.A. 1972. Catálogo de las diatomeas ar gentinas; 1.Diatomeas de aguas continentales. Buenos Aires, Comisiòn de Investigaciones de la Provincia de Buenos Aires. 301p.

MOREIRA FILHO, H.; ALENTE MOREIRA, I.M. 1981. Avaliação taxonômica e ecológica das diatomáceas (Bacillariophyceae) epifitas em algas pluricelulares obtidas nos 
litorais dos estados do Paraná ,Santa Catarina e São Paulo. Bol. Mus, Bot. Mun., Curitiba (47):1-17.

MOREIRA-FILHO, H, 1982. Introdução ao estudo das Bacillariophyceae (Diatomaceas) Curitiba,pt.1, 38p. Mimeog.

MOREIRA FILHO, H: VALENTEMOREIRA, I.M.; SOUZAMOSIMANN, R.M.DE 1985. Catálogo das Diatomáceas (ChrysophytaBacillariophyceae) Marinhas e Estuarinas do Estado de Santa Catarina, Brasil. Insula, Florianópolis, 15:33-88.

MOREIRA FILHO, H; VALENTE-MOREIRA, I.M.; CUNHA, J.A.; RODRIGUES, L. 1993. Estudos preliminares sobre a avaliação taxinômica e ecológica das Diatomáceas (Chrysophyta Bacillariophyceae), marinhas e estuarinas nos Estados de São Paulo e Rio de Janeiro,Brasil. Est. Biol. Curitiba,32:5-52.

PATRICK, R. 1940a. Diatoms of northeastern Brazil.Part 1-Coscinodiscaceae, Fragilariaceae and Eunotiaceae. Proc. Acad. Nat. Sci. Phil., Philadelphia, 92: 191-226.

PATRICK, R. 1940. Some new diatoms from Brazil,Notut,Nat., Philadelphia. 59:1-7.

PATRICK, R. 1958. Some nomenclatural problems and new species a new variety in genus Eunotia (Bacillariophyceae). Notul. Nat., Philadelphia. 312:1-15.

PATRICK, R.; REIMER., C. 1966. The diatoms of the united States, exclusive of Alaska and Hawaii. Philadelphia, Livingston. Vol.I.(Monogr. Acad. Nat.Sci. Philadelphia 13).

PATRICK, R.\& REIMER, C. 1975. The diatoms of the United States., exclusive of Alaska and Hawaii.Philadelphia, Livingston. Vol.II. (Monogr. Acad. Nat. Sci. Philadelphia.13).

RODRIGUES, L. 1984. Contribuição ao conhecimento das Diatomáceas do Rio Tubarão-Santa Catarina-Brasil. Insula, Florianópolis, (14):47-120.
SCHMIDT, A.et al. 1874-1959. Atlas der Diatomaceen-Kunde. Leipzig, O, R. Reisland. 480 est.

SILVA, R.L. 1987. Estudo taxonômico das Diatomáceas (Bacillariophyceae) coletadas no Arrôio do Faxinal Sanga da água Boa), Torres, Rio Grande do Sul, Brasil. Insula, Florianópolis, (17):1-174.

SIMONSEN, R.1974.The diatom plankton of the Indian Ocean Expedition of R/ V"Meteor" 1964-1965. "Meteor" Forsch,-Ergebnisse, Berlin, 19:1-107.

SIMONSEN, R. 1979. The diatom system:ideas on Phylogeny. Bacillaria, Brauschweig, 2:9-71.

TORGAN, L. C.; BIANCAMANO, M.I. 1991. Catálogo das Diatomáceas (Bacillariophyceae) referidas para o estado do Rio Grande do Sul ,Brasil,no periodo de 1973 a 1990 .Caderno de Pesquisa. ser. Bot., Sta Cruz do Sul.(3)1:1-201.

UHERKOVICH, G;; SCHMIDT,G.W, 1974. Phytoplanktontaxa in dem $\mathrm{Z}$ e n t r a 1 a m a zon is che $n$ Schwemmlandsee Lago do Castanho. Amazoniana. 5:243-283.

UHERKOVICH,G. 197 Algen aus den Flussen Rio Negro und Tapajós. Amazoniana 5:465-515.

UHERKOVICH,G,; RAI,H. 1979. Algen aus dem Rio Negro und seinen Nebenflussen Amazoniana Plon.VI (4):611-638.

UHERKOVICH,G.; FRANKEN,M. 1980. Aufwuchsalgen aus zentralamazonischen Regenwaldbachen. Amazoniana, (VII) 1:49-79.

VAN HEURCK,H. 1880-1881. Synopsis des Diatomées de Belgique;tex.Anvers.235p.

VAN HEURCK,H. 1896, A treatrise on the diatomaceae.London, Willian Wesley. 558p.

VANLANDINGHAM, S. L. 1967-1979. Catalogue of the fossil and recent genera and species of Diatoms and their synonyms. Lehre, J. Cramer, 8 partes. $4654 \mathrm{p}$. 